Research Article

\title{
Study on Failure Process and Permeation Evolution of Single-Cracked Rock
}

\author{
Xiangxi Meng $(\mathbb{D}$ and Weitao Liu $(\mathbb{D}$ \\ College of Mining and Safety Engineering, Shandong University of Science and Technology, Qingdao, Shandong 266590, China \\ Correspondence should be addressed to Weitao Liu; skdlwt@126.com
}

Received 23 November 2017; Revised 23 March 2018; Accepted 5 April 2018; Published 16 April 2018

Academic Editor: Fernando Lusquiños

Copyright (C) 2018 Xiangxi Meng and Weitao Liu. This is an open access article distributed under the Creative Commons Attribution License, which permits unrestricted use, distribution, and reproduction in any medium, provided the original work is properly cited.

\begin{abstract}
To evaluate the mechanical properties and permeation evolution of cracked rock mass, failure evolution tests were designed by RFPA software for single-cracked rock mass with (i) different inclination angles under uniaxial compression and (ii) different confining pressures and pore pressures under triaxial compression. The results show the following: (1) Angle of the crack significantly affects the crack propagation mode and slightly affects the bearing capacity of rock. During the crack propagation, the peak of permeation is delayed at the peak of stress. The stress-strain curve shows a different behavior in the postcritical part of the curve, especially in the case of $45^{\circ}$, where a smooth postcritical curve was clearly observed instead of an abrupt decrease in the stress of other two cases. (2) When the confining pressure is constant, the trend is almost the same when varying pore pressures, and with the increase in pore pressure, crack propagation is accelerated. At a low confining pressure, the crack is extended vertically to the upper and lower ends of the specimen, forming a longitudinal macroscopic crack. At a high confining pressure, the crack gradually extends to the left and right boundaries of the specimen, forming a transverse macroscopic crack. (3) The rate of crack initiation and destruction first decreases and then increases with the increase in confining pressure when pore pressure is constant.
\end{abstract}

\section{Introduction}

Safe and efficient green mining of coal resources is important for the national economy and social development in China. However, the geological conditions of coal mine in China are very complex, and water inrush [1-3] has been one of the important factors to hinder the production of coal. Water inrush is affected by many factors, for example, water abundance of aquifer, geological structure, and impedance water capacity of floor aquifer. Geological structure, especially the crack structure $[4,5]$, is the main cause of water inrush, closely related to the permeation of rock mass. In nature, rock is a defective body with many tiny cracks, holes, or other structures. Therefore, rock has the characteristics of discontinuity, heterogeneity, and inhomogeneity. Under the combined action of load and fluid pressure, preexisting weaknesses can close, open, extend, or induce new cracks, which can in turn change the structure of the rock and alter its fluid flow properties [6-11]. Further, skeleton grains of rock will shrink or expand, which will change its permeation characteristics. After the permeability of rock has increased, the confined water of floor is promoted to the area with large permeability. Finally, the channel of water inrush forms. Since the permeation of Westerly granite under a high pressure was investigated through experimental testing by Brace et al. [12], similar laboratory studies in this field have been extensively conducted in different types of rock, for example, by Shiping et al. [13], Wang and Park [14], and Oda et al. [7] in granite; by Wang et al. [15] for coal.

Some theoretical and numerical investigations on the realistic failure process analysis of rock mass have been widely reported. Eftekhari et al. [16] studied the crack propagation in the rock specimen with the inclined crack under uniaxial compression and found that the crack growth direction was deviated from the initial crack direction and propagated from the crack tip toward the loading plates. Yuan and Harrison 
[17] reviewed previous research and summarized that the following three main methods were employed to model the progressive mechanical breakdown of rock and associated fluid flow in rock: discrete models based on crack mechanics. $\mathrm{Xu}$ and Yang [18] established the constitutive model for fissured rock mass based on the deformation characteristics of microcracks under compression.

Tang et al. [9] set up a flow-stress-damage (FSD) coupling model for heterogeneous rocks based on a statistical model that considers the growth of existing cracks and the formation of new cracks. This model was coded into a twodimensional realistic failure process analysis (F-RFPA2D) by Yang et al. [19] to simulate hydraulic fracturing in permeable rock, and then it was extended to three dimensions by $\mathrm{Li}$ et al. [20]. Zhu et al. [21] studied the effects of axial static stress and dynamic stress on the damage and failure process of rock by RFPA and found that the simulation results were closely related to the rock heterogeneity and were in qualitative agreement with that observed in laboratory SHPB tests. Chen et al. [22] carried out a series of triaxial compression tests with permeation measurements under different confining pressures and pore pressure difference coupling conditions and found that the shapes of stressstrain curves, permeation evolution curves, and failure patterns are significantly affected by the confining pressure but are only slightly affected by the pore pressure difference. Thus, the results of previous research deepen the understanding of the realistic failure process of rock mass and provide several theoretical methods for the numerically simulating corresponding issues.

However, the relationship between failure characteristics and permeation evolution at different angles, confined pressures, and pore pressures has been rarely studied. Therefore, in this study, the tests for cracked rock mass at different inclination angles under uniaxial compression and different confining pressures and pore pressures under triaxial compression were designed by RFPA software to analyze the relationship between failure characteristics and permeation evolution. The results of this study are expected to provide a valuable reference for excavation in geotechnical engineering and protection of water inrush.

\section{Model of Single-Crack Propagation}

At present, crack propagation of brittle materials occurs through (i) tension crack and (ii) slide crack. The sliding crack model indicating the crack mechanism of microcracks is gradually taking the dominant position in explaining the microcrack propagation of brittle materials and accepted by the academic community. Brace and Bombolakis [23] first proposed the sliding crack model; then, it was popularized by Horii and Nemat-Nasser [24] to study the mechanics of crack brittle materials under compression conditions.

2.1. Single-Crack Propagation Model under Triaxial Stress. As shown in Figure 1, for a crack with a length of $2 a$ inside an infinite plate in the plane, the model was subjected to an axial

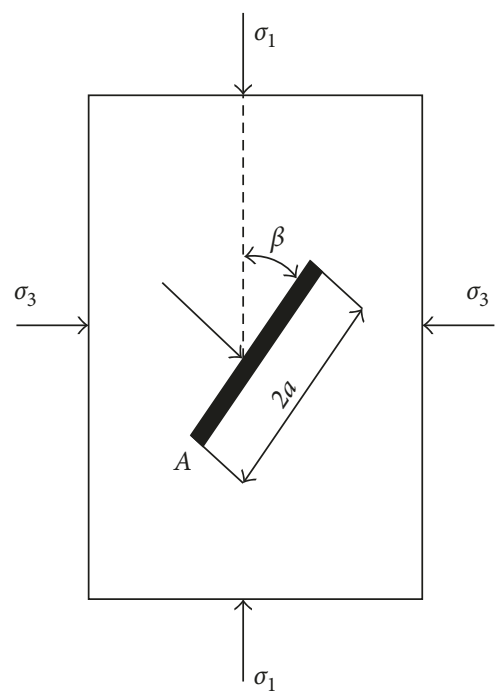

FIGURE 1: Single-crack force model under triaxial compression.

pressure of $\sigma_{1}$ and a confining pressure of $\sigma_{3}$; the angle between crack surface and axial stress is $\beta$; the internal cohesion of the crack is $c_{\mathrm{w}}$; the internal friction angle is $\psi_{\mathrm{w}}$; the internal cohesion of rock is $c$; and the internal friction angle of rock is $\psi$ [25]. The stress and shear stress of the crack can be shown as follows:

$$
\begin{aligned}
& \sigma_{n}=\frac{\sigma_{1}+\sigma_{3}}{2}-\frac{\sigma_{1}-\sigma_{3}}{2} \cos 2 \beta, \\
& \tau_{n}=\frac{\sigma_{1}-\sigma_{3}}{2} \sin 2 \beta .
\end{aligned}
$$

According to the theory of elastic crack mechanics and judgment basis of shear crack under a pressure condition $\left(k_{\Pi}=k_{\Pi c}\right)$ [26], the initial crack strength of the crack can be expressed as follows:

$$
k_{\Pi c}=\sqrt{\pi a}\left(\frac{\sigma \sin 2 \beta}{2}-\sigma f_{\mathrm{w}} \sin ^{2} \beta-f_{\mathrm{w}} c_{\mathrm{w}}\right),
$$

where $k_{\Pi c}$ is the shear toughness under compression conditions, $f_{\mathrm{w}}$ is the friction coefficient of crack, $c_{\mathrm{w}}$ is very small when the uniaxial compression, $c_{\mathrm{w}}=0$; therefore, the initial crack strength can be expressed as follows:

$$
\sigma_{\mathrm{cw}}=\frac{2 k_{\Pi \mathrm{c}}}{\sqrt{\pi a}\left[\sin 2 \beta-f_{\mathrm{w}}(1-\cos 2 \beta)\right]} .
$$

Therefore, $k_{\Pi c}$ is the critical value of stress intensity factor for crack propagation. Tests show that when $k_{\Pi}>k_{\Pi \mathrm{c}}$, the crack starts to expand.

2.2. Single-Crack Propagation Model under Pore Pressure. To simplify the analysis, Song [27] simplified the single-crack propagation model as follows: a standard specimen with a height of $100 \mathrm{~mm}$ and diameter of $50 \mathrm{~mm}$ was used. The inside of the model has a crack with a length of $l$ and an angle of $a$, and the internal crack space of the specimen is filled with pore pressure with a size of $P$, as shown in Figure 2. 
According to rock mechanics, crack tip effect and single-crack rock mass pressure shear crack criterion $\left(\lambda K_{\mathrm{I}}+K_{\mathrm{II}}=K_{\mathrm{IIC}}\right)$ and the crack strength can be expressed as follows:

$$
\sigma_{\text {crack }}=\frac{K_{\mathrm{IIC}}-\sigma_{y}\left[\left(\lambda-(1+\cos 2 a) \tan \varphi_{n}(t, w)+\sin 2 a\right)-2 P\left(\tan \varphi_{n}(t, w)-\lambda\right)+2 C_{n}(t, w)\right] \sqrt{2 \pi l}}{[(\lambda+1)(1-\cos 2 a)-\sin 2 a] \sqrt{2 \pi l}},
$$

where $\sigma_{\text {crack }}$ is the crack strength; when $\sigma_{x} \geq \sigma_{\text {crack }}$, the crack began to expand.

It can be seen from (3) and (4), under the action of compressive stress and pore pressure, the microcracks can close, open, extend, or induce new cracks, and the prefabricated cracks are relatively sliding under the action of shear stress. When the crack is activated, the tip is extended and connected through the concentrated effect, changing the permeation and strength of rock mass. Therefore, it is necessary to analyze the stress model and crack strength of cracked rock mass under stress and pore pressure.

\section{Experimental}

In this study, the numerical simulation tests were divided into two groups: (i) the crack characteristics and permeation evolution test of the single crack in different inclination angles under uniaxial compression and (ii) the relationship between failure characteristics and different confining pressures and pore pressures in single-crack specimens.

In the first numerical simulation, a numerical model was established based on the constitutive model of the MohrCoulomb mechanics. The lengths of the model's $X$ and $Y$ axes were 0.05 and $0.10 \mathrm{~m}$, respectively, with a total of 45,000 units. The model was calculated by plane strain. The inside of the model had a crack with a length of $0.02 \mathrm{~m}$ and width of $0.001 \mathrm{~m}$. The angle between the crack and horizontal direction is known as the crack angle $\beta$, and its values were $15^{\circ}, 30^{\circ}, 45^{\circ}$, $60^{\circ}$, and $75^{\circ}$, as shown in Figure 3 . The model used the standard model uniaxial compression base load. The loading type was the stress control. The initial value was 0 , and the single step increment was $0.6 \mathrm{MPa}$. A pore pressure of $0.8 \mathrm{MPa}$ was applied to the hole of crack cavity, and the water head of model's top, bottom, left, and right was 0 . The mechanical parameters of materials used in the model are shown in Table 1.

In the second numerical simulation, to study the influence of different confining pressures and different pore pressures on the failure process and permeation evolution of single-cracked rock, avoiding the impact of the crack angle on the failure process, the angle of the crack significantly affects the crack propagation mode and slightly affects the bearing capacity of rock; therefore, $\beta=45^{\circ}$ was selected for simulation in this experiment. This simulation uses the confining pressure compression under the standard mode. To verify the effect of different pore pressures and confining pressures on rock crack characteristics, pore pressures and confining pressures of this test were set as $1.0,1.5,1.8 \mathrm{MPa}$ and 2, 3, $5 \mathrm{MPa}$, respectively, as shown in Figure 4. The other boundary conditions and mechanical parameters were the same as the first simulation experiment.

\section{Results Analysis and Discussion}

\subsection{Effect of Crack Angle on Failure Characteristics and Permeation Evolution of Single Crack}

4.1.1. Crack Propagation and Pore Pressure Evolution under Uniaxial Compression. Figure 5 shows that the angle of the crack significantly affects the crack propagation mode with the increase in the crack angle, and the main crack is divided into two cracks and finally intersects with the main crack during the crack propagation. The main trends are as follows: (1) When the crack angle is small $\left(\beta=15^{\circ}\right)$, the crack propagation does not occur in the crack tip but takes place near the crack tip. The crack propagation is relatively easy before the stress reaches the peak, but the crack initiation requires a larger stress. (2) With the increase in the crack angle, the crack propagation mainly occurs at the crack tip expansion. The stress required for crack propagation first decreases and then increases with the increase in the crack angle. The direction of crack propagation is approximately perpendicular to the extension line of the main crack. As the axial pressure continues to increase, the energy starts to transfer to the main crack. The cracks are then compacted, and a stress concentration occurs at the tip of the crack parallel to the axial stress direction. The new crack is extended to the tip of the specimen, resulting in macroscopic damage to the rock specimen. (3) When $\beta=75^{\circ}$, the crack angle is almost parallel to the axial loading direction, and the direction of crack propagation is parallel to the direction of main cracks. At this time, the crack initiation is easy, but the crack propagation is strongly inhibited, increasing its peak strength. In conclusion, with the increase in the crack angle, the strength of rock first decreases and then increases, consistent with that reported by Liang et al. [28]. According to the preliminary analysis of the numerical simulation results, when $\beta=45^{\circ}$, the strength of rock may be the lowest.

According to the evolution of pore pressure, the trend of permeation evolution is consistent with that of mechanical properties. Pore pressure of model instability was $0.79 \mathrm{MPa}$; therefore, the crack angle slightly affects the bearing capacity of rock. Pore pressure in vertical $(Y)$ evolution degree is higher than the horizontal $(X)$ evolution degree, and the permeation of model in the longitudinal direction is higher than the horizontal permeation.

4.1.2. Permeation Evolution under Uniaxial Compression. The analysis indicates that with the increase in the crack angle, the strength of rock first decreases and then increases, ranging from $30^{\circ}$ to $60^{\circ}$. Therefore, to study this process, the stress-strain and flow-strain curves of $30^{\circ}, 45^{\circ}$, and $60^{\circ}$ were selected as the research object, as shown in Figure 6. 


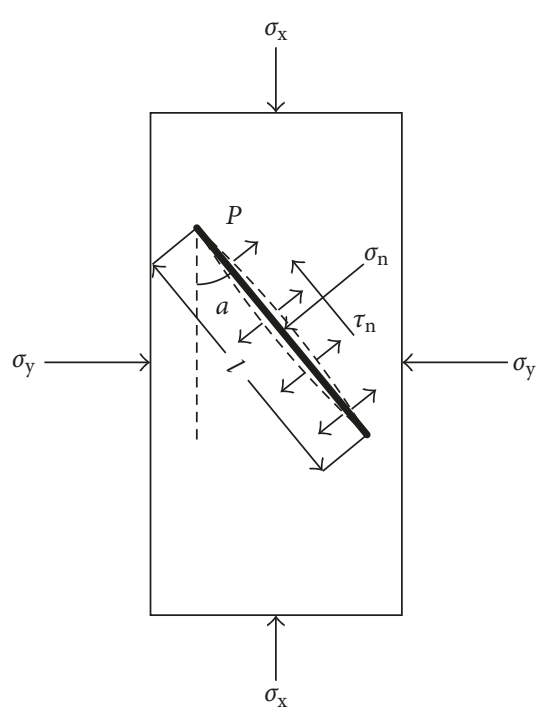

Figure 2: Compressive shear model of rock mass with the single crack under pore pressure.

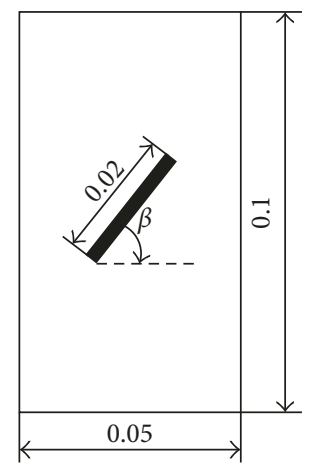

(a)

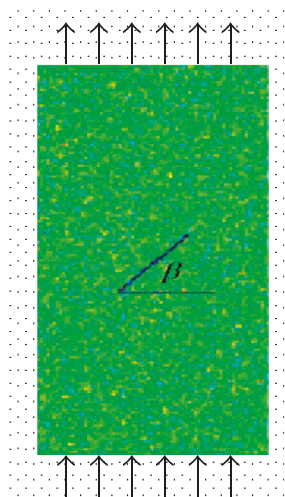

(b)
FIgURE 3: Model schematic diagram and RFPA model diagram under uniaxial compression.

TABLE 1: The mechanical parameters of materials used in the model.

\begin{tabular}{lcc}
\hline Parameter & Symbol & Value \\
\hline Homogeneous degree & $m$ & 2 \\
Elastic modulus (GPa) & $E_{\mathrm{c}}$ & 3 \\
Poisson ratio & $\mu$ & 0.25 \\
Friction angle & $\varphi$ & $32^{\circ}$ \\
The average compressive strength $(\mathrm{MPa})$ & $f_{\mathrm{c}}$ & 200 \\
Permeation coefficient $\left(\mathrm{m} \cdot \mathrm{d}^{-1}\right)$ & $K$ & 0.000864 \\
\hline
\end{tabular}

Figure 6 shows that the stress-strain curves were subjected to compaction, elastic, plastic, and residual load stages. In the early stage of axial stress loading, the original crack did not develop, and the permeation of the specimen was small. As the axial stress continued to increase, the specimen entered the plastic failure stage. The specimens are constantly destroyed, and the crack constantly sprouted, expanded, and penetrated; therefore, the permeation constantly increased. The stress-strain curve shows that after

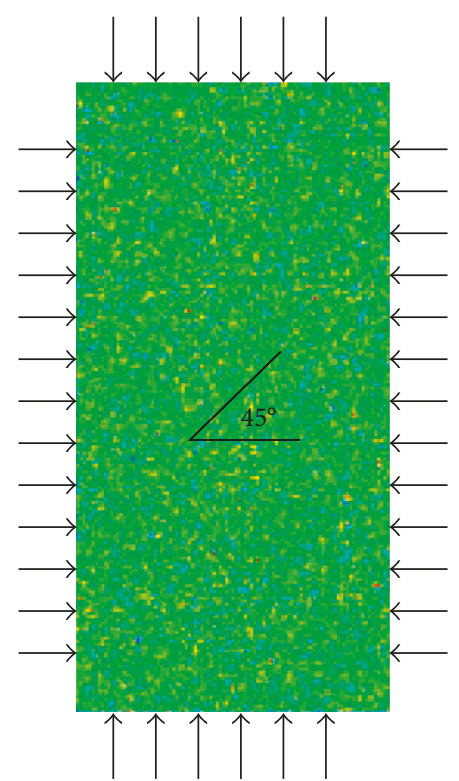

FIgURE 4: RFPA model diagram under the triaxial compression.

entering the plastic zone, pressure drop occurred in the three different angles, and the crack developed. Small cracks joined, and a big crack formed. The flow-strain curve shows that the permeation evolution and stress-strain trends are consistent, but the peak of permeation delayed at the peak of stress. During the residual load stage, the specimens can still bear axial stress, and the permeation first decreases and then maintains a higher level or continues to increase.

In addition, when $\beta=45^{\circ}$, the stress-strain curve is different from that of $\beta=30^{\circ}$ and $60^{\circ}$, and the stress-strain curve shows a different behavior in the postcritical part of the curve, especially in the case of $45^{\circ}$, where a smooth postcritical curve was clearly observed instead of an abrupt decrease in the stress of other two cases $\left(\beta=30^{\circ}\right.$ and $\left.60^{\circ}\right)$. This is because when the strength of rock decreases with the increase in strain, additional load must be delivered to the sample, as the rocks show residual strength in the postdestructive region. In the other case, the destruction process is uncontrollable, and the piston of the material testing machine must be withdrawn to stop it $[29,30]$. In addition, according to the effect of the single joint angle on the strength of the single-crack rock specimen, when $\beta$ satisfies the following (5), sliding failure along the joint plane direction occurs in the single-crack rock, and the corresponding strength is the lowest [31]. At this time, the failure of the specimen is mainly caused by the shear failure. Therefore, the stress-strain curve shows a different behavior in the postcritical part of the curve, especially in the case of $45^{\circ}$, where a smooth postcritical curve was clearly observed instead of an abrupt decrease in the stress of other two cases:

$$
90^{\circ}-\beta=45^{\circ}+\frac{\varphi}{2}=45+\frac{\arctan (\mu)}{2},
$$

where $\varphi$ is the internal friction angle of the joint plane and $\mu$ is the friction coefficient of the joint plane, which is 0 in this study. 

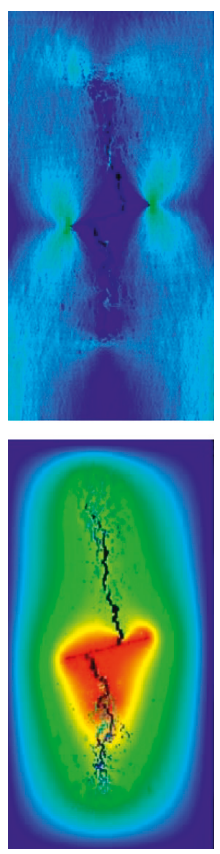

(a)
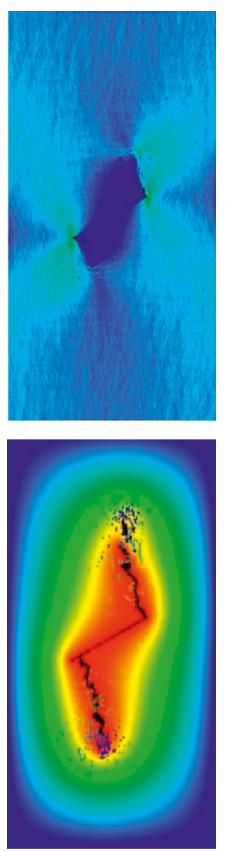

(b)
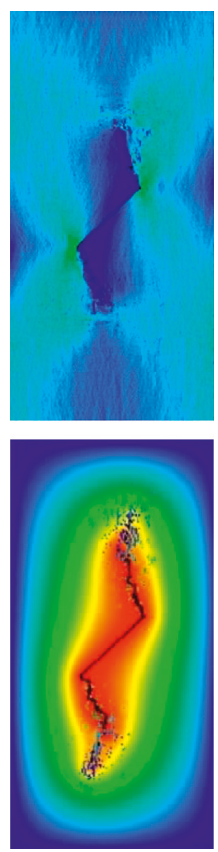

(c)
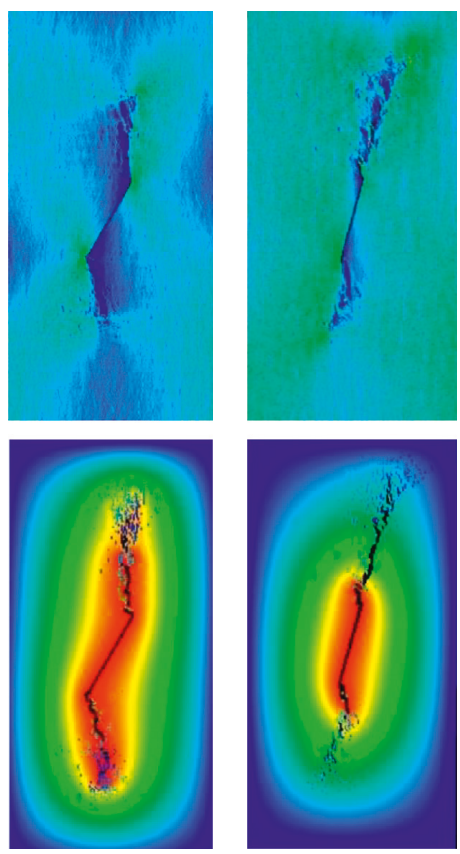

(d)

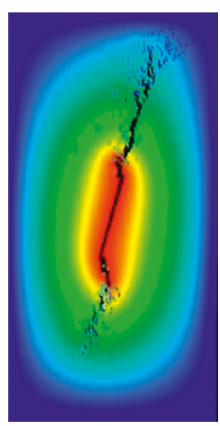

(e)

Figure 5: Maximum shear stress (upper) and pore pressure (lower) evolution diagram of different crack angle models. (a) $\beta=15^{\circ}$, step: 11-40; (b) $\beta=30^{\circ}$, step: $10-25$; (c) $\beta=45^{\circ}$, step: $10-15$; (d) $\beta=60^{\circ}$, step: $14-27$; (e) $\beta=75^{\circ}$, step: $32-18$.

Thus when $\beta$ is $45^{\circ}$, the uniaxial compressive strength of the single-crack rock specimen is the lowest. Subsequently, in this study, the uniaxial compressive strength of the rock is the lowest, and the sliding failure occurs along the joint plane within the rock body.

\subsection{Effect of Pore Pressure and Confining Pressure on Failure} Characteristics and Permeation Evolution of Single Crack. To simplify the analysis of crack propagation trend, the crack initiation and final failure of the specimen were studied in this test. Figures 7-9 show that with the increase in confining pressure, the velocity of crack initiation to failure did not increase monotonically but first decreased and then increased. However, with the increase in pore pressure, the velocity of crack initiation to failure clearly increased. A detailed analysis of this phenomenon is given below:

(1) When the confining pressure is constant, as the pore pressure increases, the velocity of crack initiation to failure clearly increased. This is because an increase in pore pressure leads to severe damage to the integrity of material inside the specimen. The crack remains on the base of the original damage and continues to grow until the specimen is eventually destroyed. The higher the pore pressure, the higher the damage to the specimen, shortening the time of the specimen being destroyed. An increase in pore pressure contributes to the development of cracks. In addition, a large difference was observed between the low and high confining pressures in the crack propagation mode. In the low confining pressure stage $(\sigma=2.0 \mathrm{MPa}$ and $3.0 \mathrm{MPa})$, the mode of crack propagation is the same as that in the previous study, that is, with the increase in axial compression, the crack tip wings start to crack and propagate in reverse direction, and the crack propagation line is at an angle and then gradually extended. Axial stress is parallel to the axial load applied to the main crack. A "wing crack" forms and vertically extends to the specimen on the lower end surface, forming a longitudinal crack. The process of crack propagation is accompanied by secondary antiwing and coplanar cracks, but the direction is approximately parallel to the axial direction. In the high confining pressure stage $(\sigma=5.0 \mathrm{MPa})$, the crack propagates at a certain angle; then, with the increase in axial pressure, the propagation direction is perpendicular to the axial stress. Finally, the crack gradually expands to the left and right boundaries of the specimen with the form of "antiwing crack," forming transverse macrocracks. This is because when the confining pressure plays a major role in the coupling process, the cracks are under confining pressure. Homogeneous specimens in the horizontal direction are significantly lower than the axial direction, and the specimens are damaged in the horizontal direction. Therefore, the direction of crack propagation changes. The cracks are gradually transformed to "antiwing cracks" form the level extended to the specimen around the border.

(2) When the pore pressure is constant, the velocity of crack initiation to failure does not increase monotonically but first decreases and then increases. This is because during the crack development, (i) new cracks are produced, (ii) original cracks disappear, 


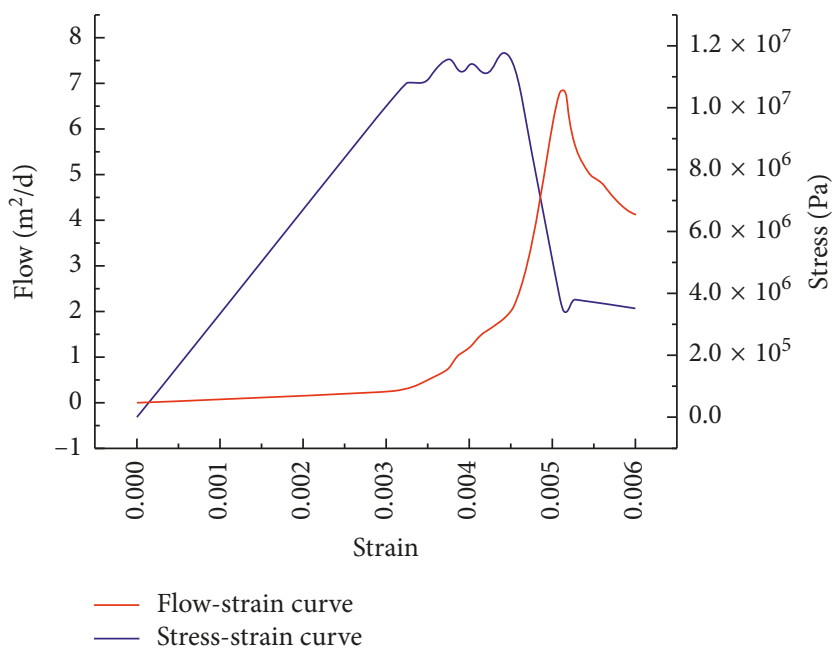

(a)

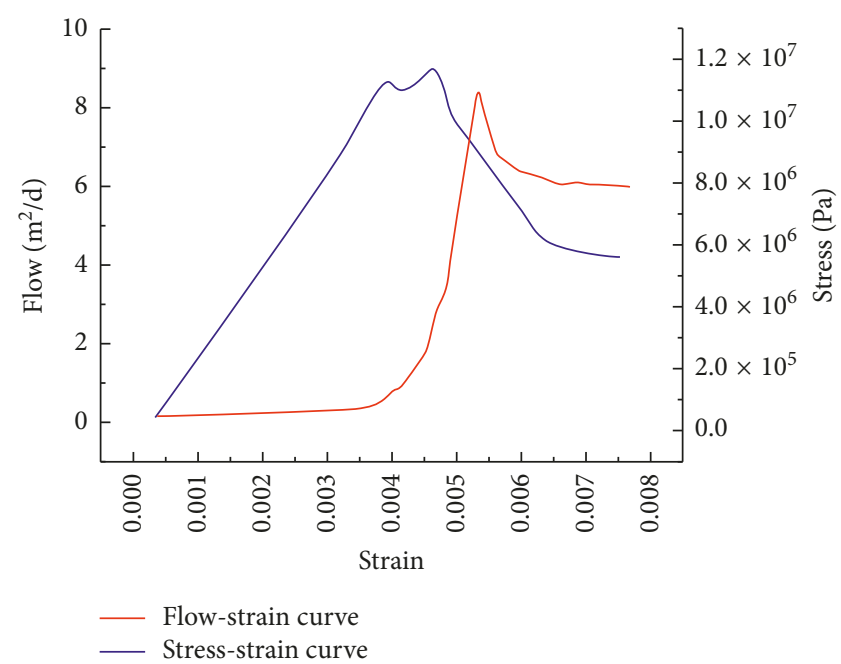

(b)

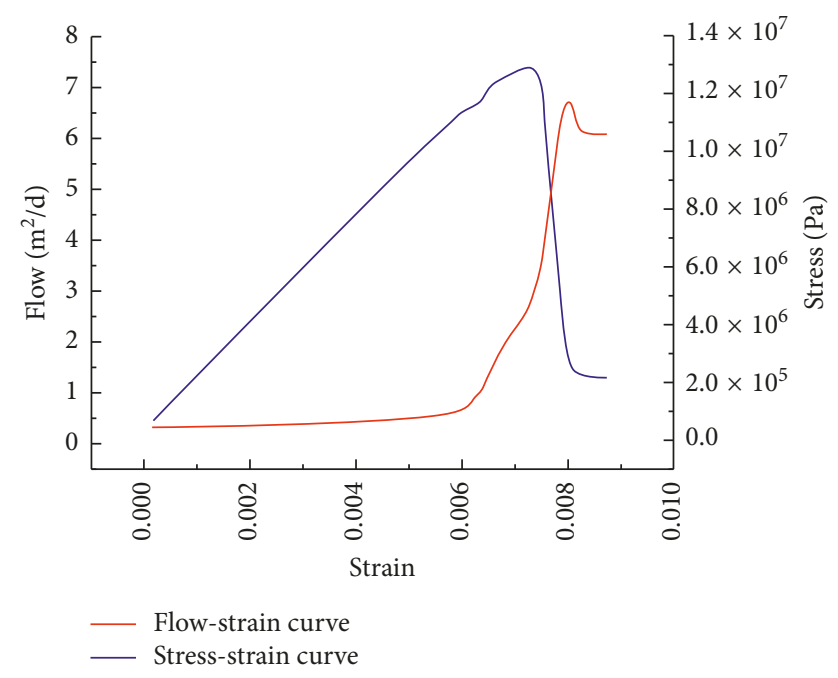

(c)

FIgURE 6: Evolution of stress and permeation under uniaxial compression with different angles. (a) $\beta=30^{\circ}$; (b) $\beta=45^{\circ}$; (c) $\beta=60^{\circ}$.

(iii) cracks propagate, and (iv) cracks interpenetrate. The four stages do not exist independently but exist together and undergo mutual transformation. Under the action of confining pressure, the small cracks are compacted, leading to the disappearance of the original crack. The homogeneity of specimens increased, and the integrity of specimens improved, leading to crack propagation. When $\sigma=3.0 \mathrm{MPa}$, the crack propagation is more than that when $\sigma=2.0 \mathrm{MPa}$. With the increase in confining pressure, the specimen severely damaged. The number of original cracks that disappeared is much smaller than the number of new cracks, and the speed of crack propagation is higher than that of disappearance of original cracks, leading to a much higher rate of crack propagation.

(3) The trend of permeation evolution is consistent with the direction of crack propagation. In the low confining pressure stage $(\sigma=2.0 \mathrm{MPa}$ and $3 \mathrm{MPa})$, the pore pressure produces cracks in the "elliptical" longitudinal direction, extending to the specimen under the surface, and the longitudinal evolution degree is greater than the lateral evolution degree. These two factors rapidly increase the permeation of the specimen in the longitudinal direction ( $Y$ direction), much higher than transverse permeation ( $X$ direction). In the high confining pressure stage $(\sigma=5.0 \mathrm{MPa})$, pore pressure extends at the level of feather shape, and the degree of lateral evolution is higher than that of longitudinal evolution. This leads to a sharp increase in the permeation of specimens in the transverse direction ( $X$ direction), much higher than that in the longitudinal direction ( $Y$ direction).

\section{Conclusions}

In this study, tests were designed by RFPA software for cracked rock mass with (i) different inclination angles under 

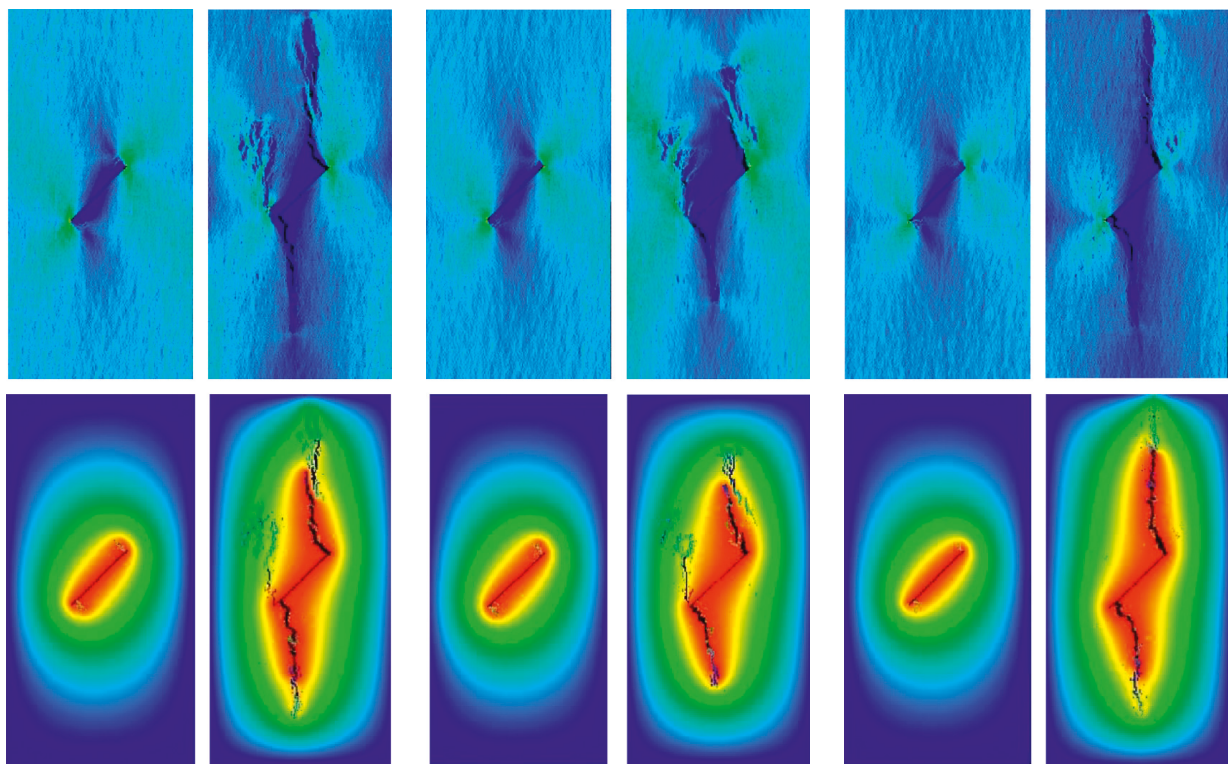

(a)

(b)
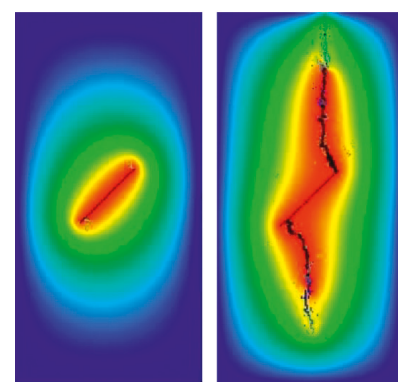

(c)

Figure 7: Maximum shear stress (upper) and pore pressure (lower) evolution diagram of different pore pressures when $\sigma=2.0 \mathrm{MPa}$. (a) $P=1.0 \mathrm{MPa}, \sigma=2.0 \mathrm{MPa}$; (b) $P=1.5 \mathrm{MPa}, \sigma=2.0 \mathrm{MPa}$; (c) $P=1.8 \mathrm{MPa}, \sigma=2.0 \mathrm{MPa}$.
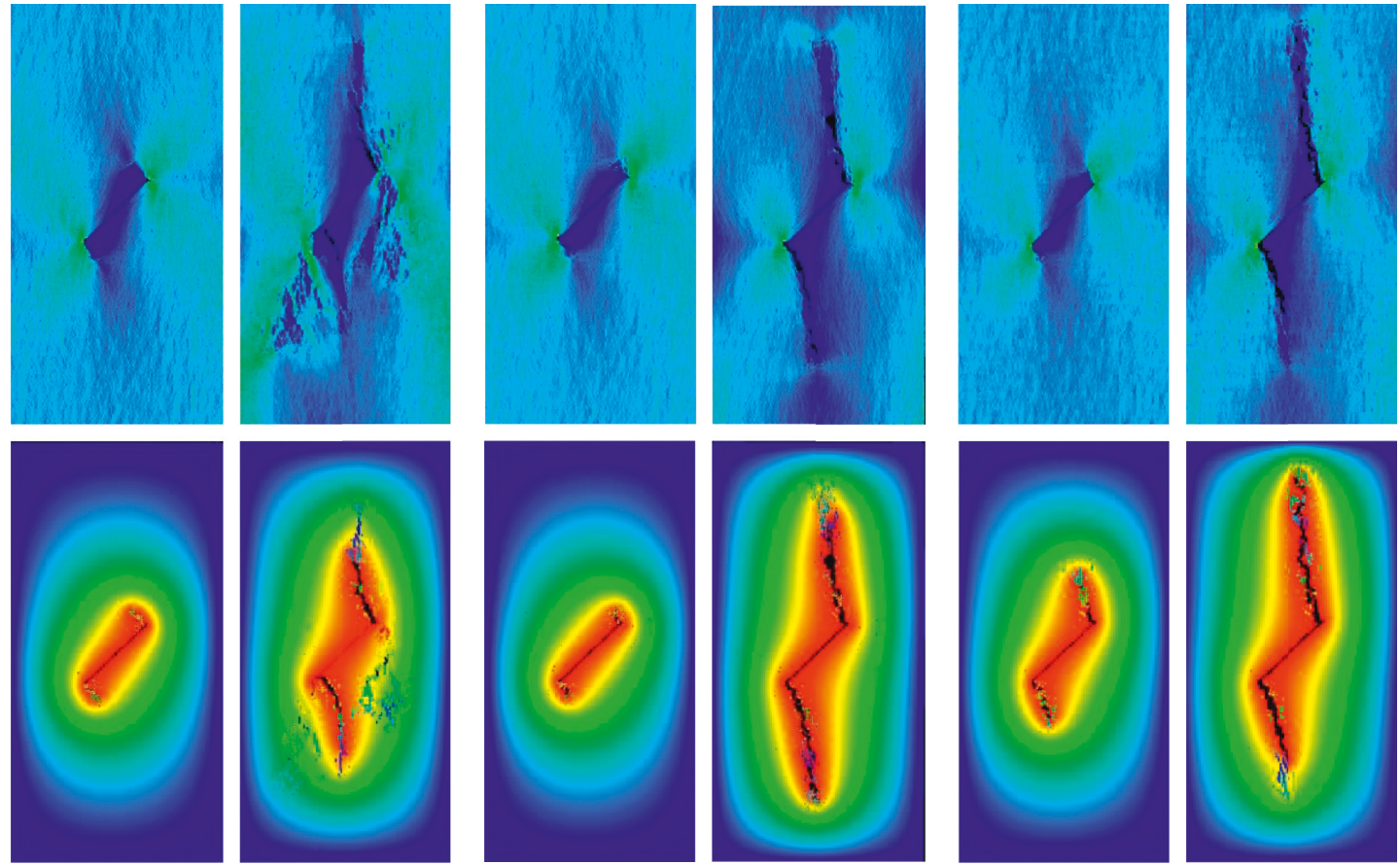

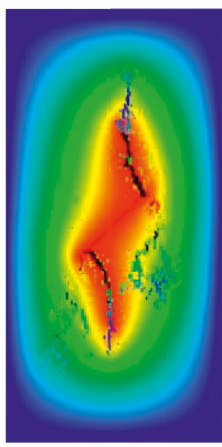

(a)
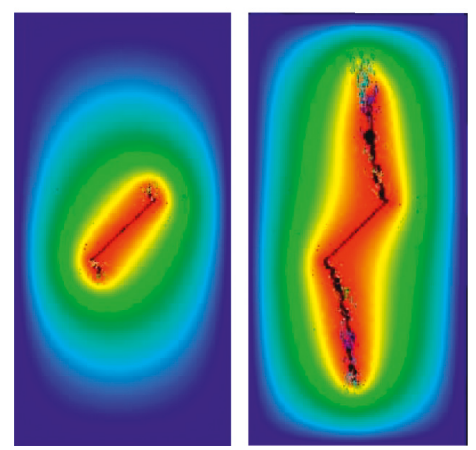

(b)
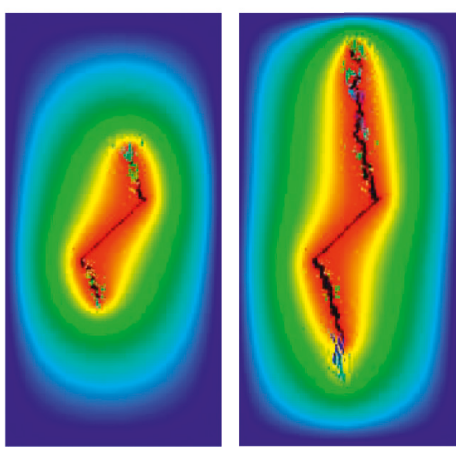

(c)

FIGURE 8: Maximum shear stress (upper) and pore pressure (lower) evolution diagram of different pore pressures when $\sigma=3.0 \mathrm{MPa}$. (a) $P=1.0 \mathrm{MPa}, \sigma=3.0 \mathrm{MPa}$; (b) $P=1.5 \mathrm{MPa}, \sigma=3 \mathrm{MPa}$; (c) $P=1.8 \mathrm{MPa}, \sigma=3 \mathrm{MPa}$.

uniaxial compression and (ii) different confining pressures and pore pressures under triaxial compression to analyze the relationship between failure characteristic and permeation evolution. Based on the above discussion, the following conclusions are drawn:
(1) Crack angle significantly affects the crack propagation mode with the increase in the crack angle and slightly affects the bearing capacity of rock; it can be divided into three modes: (i) the crack propagation does not appear in the crack tip, (ii) the direction of 

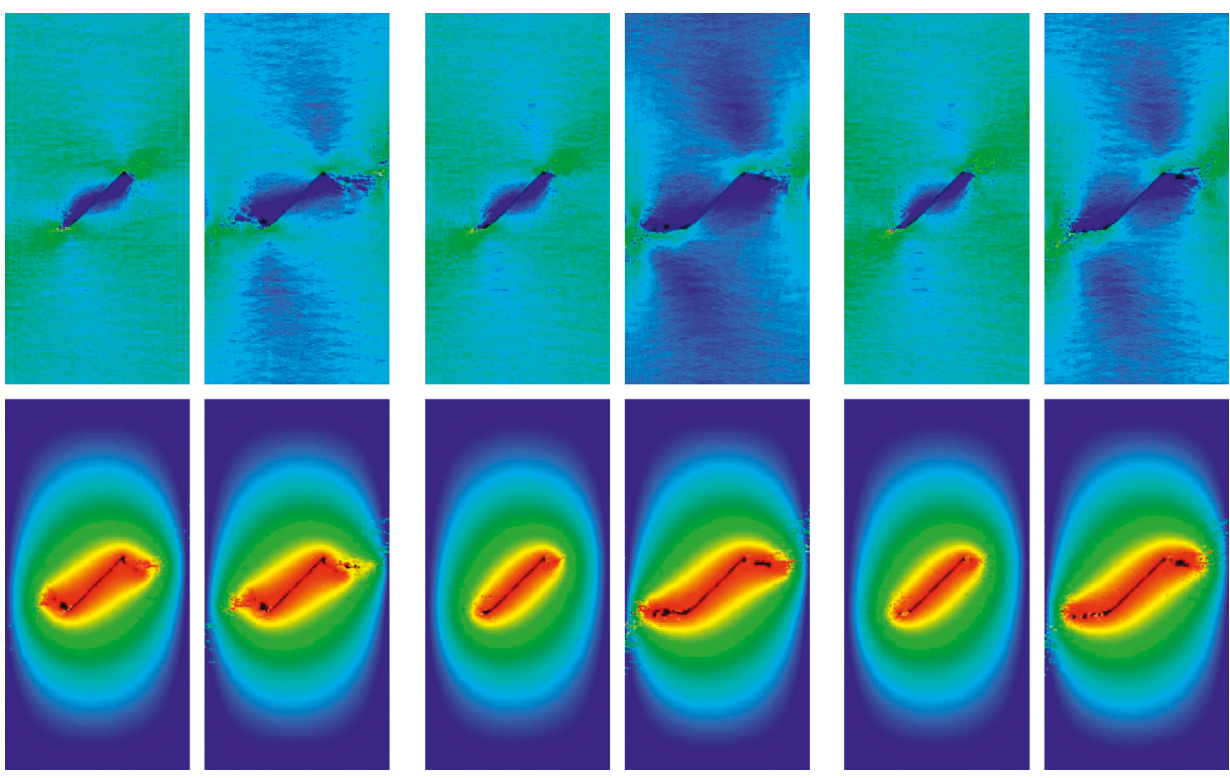

(a)

(b)

(c)

Figure 9: Maximum shear stress (upper) and pore pressure (lower) evolution diagram of different pore pressures when $\sigma=5.0 \mathrm{MPa}$. (a) $P=1.0 \mathrm{MPa}, \sigma=5.0 \mathrm{MPa}$; (b) $P=1.5 \mathrm{MPa}, \sigma=5.0 \mathrm{MPa}$; (c) $P=1.8 \mathrm{MPa}, \sigma=5.0 \mathrm{MPa}$.

crack propagation is approximately perpendicular to the extension line of the main crack, and (iii) the direction of crack propagation is parallel to the direction of the main cracks. In addition, the trend of pore pressure evolution is consistent with that of crack propagation.

(2) With the increase in the crack angle, the strength of rock first decreases and then increases. The peak of permeation is delayed at the peak of stress. The stress-strain curve shows a different behavior in the postcritical part of the curve, especially in the case of $45^{\circ}$, where a smooth postcritical curve was clearly observed instead of an abrupt decrease in the stress of other two cases $\left(\beta=30^{\circ}\right.$ and $\left.60^{\circ}\right)$.

(3) When the confining pressure is constant, as pore pressure increases, the velocity of crack initiation to failure clearly increased. There is a significant difference between the low and high confining pressures in the crack propagation mode.

(4) When the pore pressure is constant, the velocity of crack initiation to failure does not increase monotonically but first decreases and then increases. The trend of permeation evolution is consistent with the direction of crack propagation.

Therefore, the results of this study are expected to provide a valuable reference for excavation in geotechnical engineering and protection of water inrush. In addition, we will test the simulation results in the future and expect to find more discoveries on this basis.

\section{Conflicts of Interest}

The authors declare that they have no conflicts of interest.

\section{Acknowledgments}

This study was supported by the Graduate Student Science and Technology Innovation Project of Shandong University of Science and Technology (SDKDYC180101).

\section{References}

[1] L. Lianchong, Y. Tianhong, L. Zhengzhao, Z. Wancheng, and T. Chunan, "Numerical investigation of groundwater outbursts near faults in underground coal mines," International Journal of Coal Geology, vol. 85, no. 3-4, pp. 276-288, 2011.

[2] Q. Wu, M. Wang, and X. Wu, "Investigations of groundwater bursting into coal mine seam floors from fault zones," International Journal of Rock Mechanics and Mining Sciences, vol. 41, no. 4, pp. 557-571, 2004.

[3] X. X. Meng, W. T. Liu, and D. R. Mu, "Influence analysis of mining's effect on failure characteristics of a coal seam floor with faults: a numerical simulation case study in the Zhaolou coal mine," Mine Water and the Environment, vol. 2018, pp. 1-9, 2018.

[4] L. J. Donnelly, "A review of coal mining induced fault reactivation in Great Britain," Quarterly Journal of Engineering Geology and Hydrogeology, vol. 39, no. 1, pp. 5-50, 2006.

[5] J. S. Caine, J. P. Evans, and C. B. Forster, "Fault zone architecture and permeation structure," Geology, vol. 24, no. 11, pp. 1025-1028, 1995.

[6] C. Ö. Karacan, G. S. Esterhuizen, S. J. Schatzel, and W. P. Diamond, "Reservoir simulation-based modeling for characterizing longwall methane emissions and gob gas venthole production," International Journal of Coal Geology, vol. 71, no. 2-3, pp. 225-245, 2007.

[7] M. Oda, T. Takemura, and T. Aoki, "Damage growth and permeation change in triaxial compression tests of Inada granite," Mechanics of Materials, vol. 34, no. 6, pp. 313-331, 2002. 
[8] O. Schulze, T. Popp, and H. Kern, "Development of damage and permeation in deforming rock salt," Engineering Geology, vol. 61, no. 2-3, pp. 163-180, 2001.

[9] C. A. Tang, L. G. Tham, P. K. K. Lee, T. H. Yang, and L. C. Li, "Coupling analysis of flow, stress and damage (FSD) in rock failure," International Journal of Rock Mechanics and Mining Sciences, vol. 39, no. 4, pp. 477-489, 2002.

[10] T. F. Wong, C. David, and W. Zhu, "The transition from brittle faulting to cataclastic flow in porous sandstones: mechanical deformation," Journal of Geophysical Research Solid Earth, vol. 102, no. B2, pp. 3009-3025, 1997.

[11] B. F. Lu and Y. J. Xiao, "Study on lithological division of coal bearing fractured aquifer in Heilongjiang province," Journal of Shandong University of Science and Technology, vol. 36, no. 6, pp. 96-102, 2017.

[12] W. F. Brace, J. B. Walsh, and W. T. Frangos, "Permeation of granite under high pressure," Journal of Geophysical Research, vol. 73, no. 6, pp. 2225-2236, 1968.

[13] L. Shiping, L. Yushou, L. Yi, W. Zhenye, and Z. Gang, "Permeation-strain equations corresponding to the complete stress-strain path of Yinzhuang sandstone," International Journal of Rock Mechanics and Mining Science \& Geomechanics Abstracts, vol. 31, no. 4, pp. 383-391, 1994.

[14] J. A. Wang and H. D. Park, "Fluid permeation of sedimentary rocks in a complete stress-strain process," Engineering Geology, vol. 63, no. 3-4, pp. 291-300, 2002.

[15] S. Wang, D. Elsworth, and J. Liu, "Permeation evolution during progressive deformation of intact coal and implications for instability in underground coal seams," International Journal of Rock Mechanics and Mining Sciences, vol. 58, pp. 34-45, 2013.

[16] M. Eftekhari, A. Baghbanan, and H. Hashemolhosseini, "Crack propagation in rock specimen under compressive loading using extended finite element method," Arabian Journal of Geosciences, vol. 9, no. 2, pp. 1-10, 2016.

[17] S. C. Yuan and J. P. Harrison, "A review of the state of the art in modelling progressive mechanical breakdown and associated fluid flow in intact heterogeneous rocks," International Journal of Rock Mechanics and Mining Sciences, vol. 43, no. 7, pp. 1001-1022, 2006.

[18] P. Xu and S. Q. Yang, "A fracture damage constitutive model for fissured rock mass and its experimental verification," Arabian Journal of Geosciences, vol. 10, no. 7, p. 164, 2017.

[19] T. H. Yang, L. G. Tham, C. A. Tang, Z. Z. Liang, and Y. Tsui, "Influence of heterogeneity of mechanical properties on hydraulic fracturing in permeable rocks," Rock Mechanics and Rock Engineering, vol. 37, no. 4, pp. 251-275, 2004.

[20] L. C. Li, C. A. Tang, G. Li, S. Y. Wang, Z. Z. Liang, and Y. B. Zhang, "Numerical simulation of 3D hydraulic fracturing based on an improved flow-stress-damage model and a parallel fem technique," Rock Mechanics and Rock Engineering, vol. 45, no. 5, pp. 801-818, 2012.

[21] W. C. Zhu, Y. Bai, X. B. Li, and L. L. Niu, "Numerical simulation on rock failure under combined static and dynamic loading during SHPB tests," International Journal of Impact Engineering, vol. 49, no. 2, pp. 142-157, 2012.

[22] X. Chen, J. Yu, C. A. Tang, H. Li, and S. Wang, "Experimental and numerical investigation of permeation evolution with damage of sandstone under triaxial compression," Rock Mechanics and Rock Engineering, vol. 50, no. 6, pp. 1529-1549, 2017.

[23] W. F. Brace and E. G. Bombolakis, "A note on brittle crack growth in compression," Journal of Geophysical Research, vol. 68, no. 12, pp. 3709-3713, 1963.

[24] H. Horii and S. Nemat-Nasser, "Compression-induced microcrack growth in brittle solids: axial splitting and shear failure,"
Journal of Geophysical Research Solid Earth, vol. 90, no. B4, pp. 3105-3125, 1985.

[25] Y. P. Li, Y. L. Wu, and C. H. Yang, "Comparison of sliding crack models for rock-like materials," Chinese Journal of Rock Mechanics and Engineering, vol. 26, no. 2, pp. 278-284, 2007.

[26] H. Wang, Numerical Simulation of Cracked Rock Failure Process and Related Laws, Anhui University of Science and Technology, Huainan, China, 2015.

[27] W. C. Song, Study on Crack Characteristics of Rock Mass and Water Inrush Process in Mining Floor, Shandong University of Science and Technology, Qingdao, China, 2017.

[28] Z. Liang, C. A. Tang, H. X. Li, T. Xu, and T. H. Yang, "A numerical study on failure process of transversely isotropic rock subjected to uniaxial compression," Rock and Soil Mechanics, vol. 26, no. 1, pp. 57-62, 2005.

[29] M. Bukowska, "Post-peak failure modulus in problems of mining geo-mechanics," Journal of Mining Science, vol. 49, no. 5, pp. 731-740, 2013.

[30] A. Bogusz and M. Bukowska, "Stress-strain characteristics as a source of information on the destruction of rocks under the influence of load," Journal of Sustainable Mining, vol. 14, no. 1, pp. 46-54, 2015.

[31] X. S. Tan, X. F. Xian, D. F. Zheng, and Y. Z. Zhao, Theory and Application of Compound Rock Mass Mechanics, China Coal Industry Publishing House, Beijing, China, 1994. 


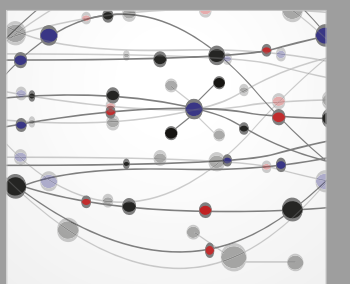

The Scientific World Journal
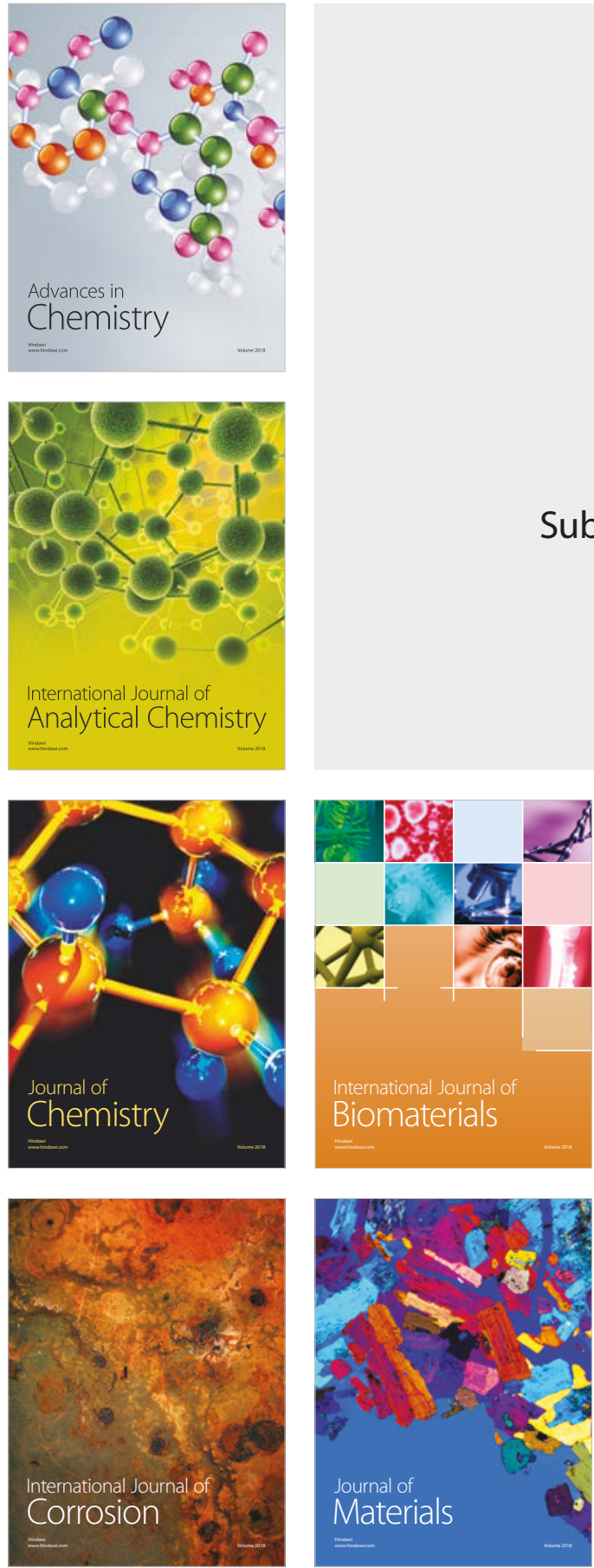

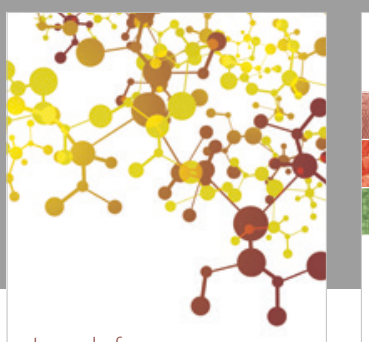

Journal of

Applied Chemistry
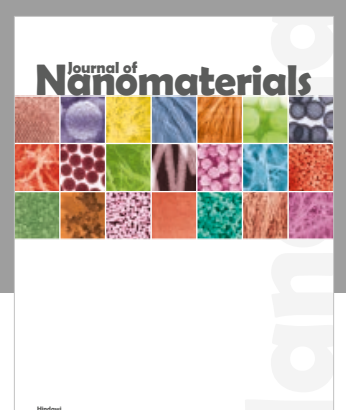

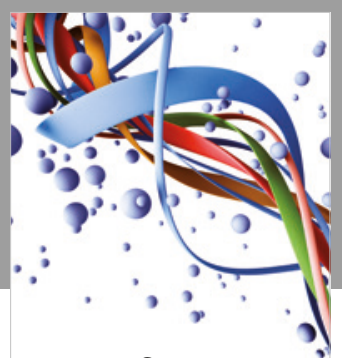

Scientifica

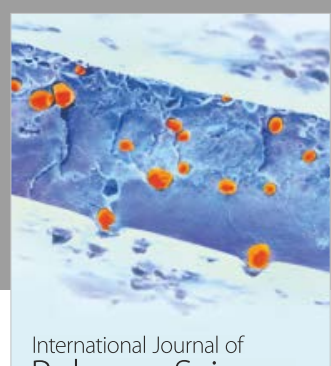

Polymer Science

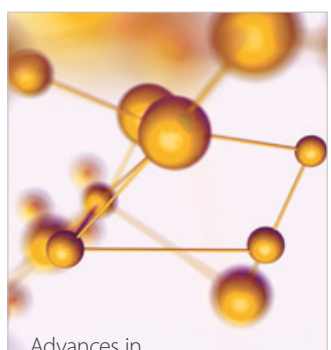

Physical Chemistry
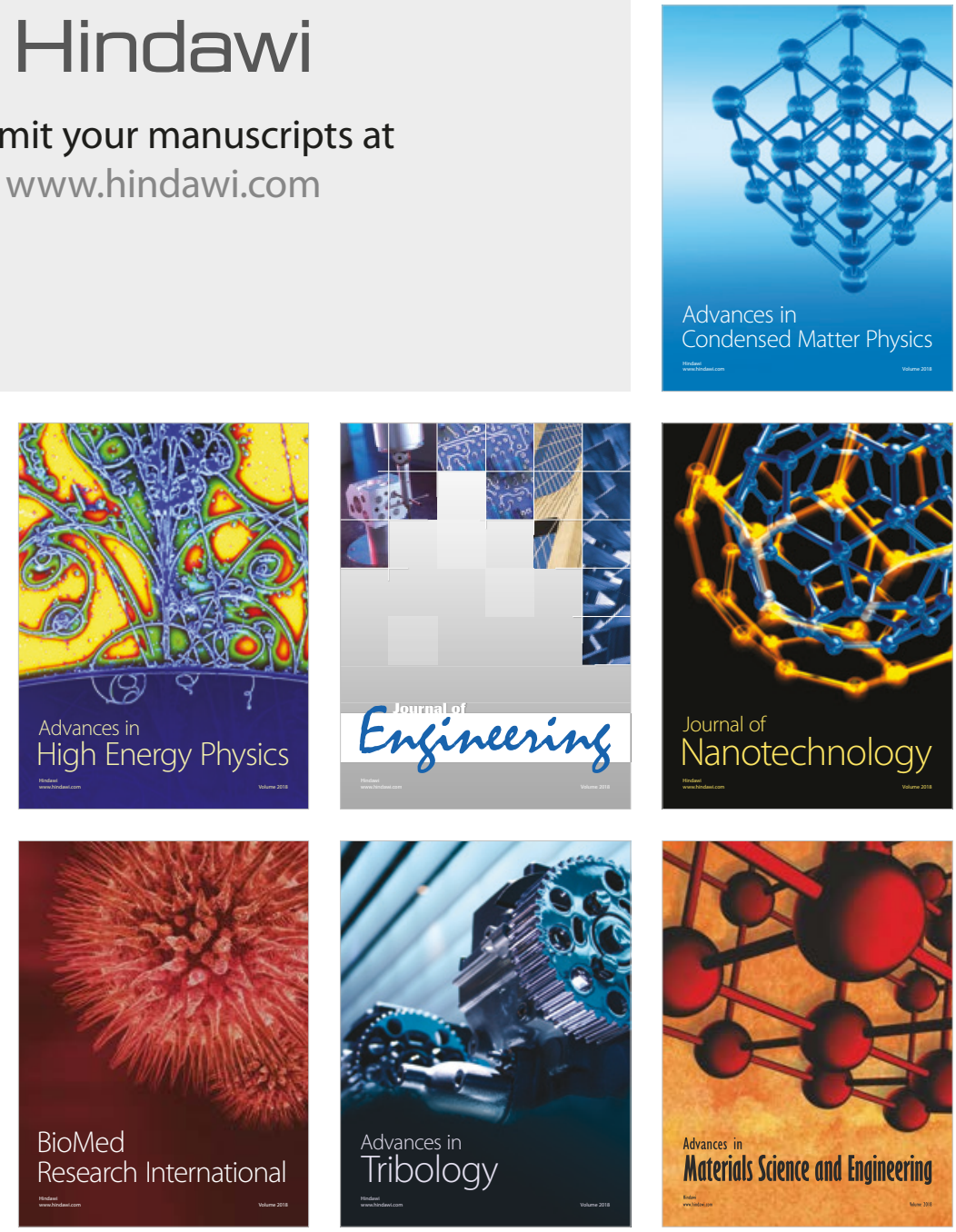